\title{
ENSINO SUPERIOR PUBLICO E AS NOVAS POLITICAS DE EXPANSÃO E DE INCLUSÃO: O PROGRAMA UNIVESP
}

\section{Carlos Vogt}

CDD: 378

\section{RESUMO}

No Brasil, a importância da educação superior como forma de produção de conhecimento e de profissionalização tem se intensificado. Tendo consolidado o funcionamento desse sistema, as políticas do Estado de São Paulo voltadas para a área de ensino superior tem investido em programas de expansão do ensino superior para ampliar o número de vagas oferecidas e de ampliar sua distribuição geográfica. Diante dos limites físicos de expansão do ensino superior público paulista emerge a proposta do ensino virtual - uma concepção de educação que ultrapassa os limites geográficos - por meio do programa Universidade Virtual do Estado de São Paulo - UNIVESP. O programa, como abordado no presente artigo, amplia o número de vagas nas três universidades públicas paulistas - USP, UNICAMP E UNESP - utilizando metodologia inovadora, que associa o uso intensivo das tecnologias de informação e comunicação às práticas tradicionais do ensino presencial, o que permite uma grande qualidade na formação dos alunos.

\section{PALAVRAS-CHAVE}

Educação superior; Educação a distância; Tecnologias de informação e comunicação; Ensino presencial; UNIVESP

\section{PUBLIC HIGHER EDUCATION AND THE NEW POLICIES OF EXPANSION AND INCLUSION: THE UNIVESP PROGRAM}

\begin{abstract}
In Brazil, the importance of university education as a way of producing knowledge and accomplishing professional abilities is facing a significant increase. In view of that, the Government of State of São Paulo has been adopting policies with a view to investing in programs of expansion of university education, aiming at both increasing the number of people able to attend the university courses and expanding the geographic distribution of such courses. Due to the physical limits imposed to the expansion of public university education in the State of São Paulo, a new concept arises - the virtual education system, offered by the program called "Virtual University of the State of São Paulo". A concept of education that exceeds geographic limits. Such program, as one may infer from this essay, allows an increase in the number of people attending university courses at the three main public universities in São Paulo - USP, UNICAMP and UNESP - by using innovative methodology, which associates the intensive use of the information and communication technologies to the traditional practices of the teacher-student relationship with the quality of the university education.
\end{abstract}

\section{KEYWORDS}

Higher education; Distance education; Information and communication technologies; Teacherstudent relationship; UNIVESP 


\section{INTRODUÇÃO}

Alison Wolf, professor de educação na Universidade de Londres, no livro Does education matter? Myths about education and economic growth (A educação importa? Mitos sobre a educação e o crescimento econômico), a propósito do sistema educacional britânico, chama a atenção para o risco de se tratar a questão apenas do ponto de vista quantitativo e dentro de uma lógica de causalidade simplista entre educação e crescimento econômico.

Para diminuir esse aspecto utilitarista da cultura e da educação é preciso reduzir as conseqüências perversamente sistemáticas das economias globalizadas no que diz respeito à distribuição de renda e à justiça social.

Para países como o Brasil, ainda em passo de emergência, o problema se agrava, entre outras coisas, pelo baixo índice de produção tecnológica e de inovação competitiva nos mercados internacionais e por falta de agregação de valor à maioria de nossos produtos de exportação. Desse modo, cumpre, mais do que nunca, a todos os atores sociais ligados à educação e à produção científica e tecnológica, governos, instituições de ensino e de pesquisa, agências de fomento, a sociedade civil, como um todo, o trabalho pela universalização do acesso ao conhecimento, com propostas eficazes em número e em qualidade.

No Brasil, a importância da educação superior como forma de produção de conhecimento e de profissionalização para ingresso no mercado de trabalho tem se intensificado. O Estado de São Paulo é pioneiro no cenário, abrigando a maior rede de instituições de pesquisa do país, responsável por 55\% da produção científica nacional. Esse desempenho é resultado de uma política pautada pela autonomia das instituições de ensino superior, de investimentos na qualidade dos sistemas de graduação, pós-graduação e extensão e de fomento à pesquisa.

Hoje, São Paulo reúne um conjunto heterogêneo de 25 universidades, dentre as quais seis universidades federais, 16 universidades privadas (que fazem pesquisa) e três universidades estaduais: a Universidade de São Paulo (USP), a Universidade Estadual de Campinas (UNICAMP) e a Universidade Estadual Paulista "Júlio de Mesquita Filho" (UNESP), vinculadas à Secretaria de Ensino Superior do Estado de São Paulo (SES-SP). O Estado de São Paulo também conta duas faculdades estaduais, a Faculdade de Medicina de Marília (FAMEMA) e a Faculdade de Medicina de São José do Rio Preto (FAMERP), ambas 
vinculadas à SES-SP, além de 45 Faculdades de Tecnologia (FATECs) e 25 instituições de ensino superior municipais.

Tendo consolidado a organicidade e o funcionamento desse sistema, as políticas do Estado de São Paulo voltadas para a área de ensino superior tem investido em programas de expansão do ensino superior com o objetivo de ampliar o número de vagas oferecidas e de contribuir para a ampliação de sua distribuição geográfica.

Diante dos limites físicos de expansão do ensino superior público paulista e da necessidade de se atingir todos os pontos do Estado, emerge a proposta do ensino virtual, uma concepção de educação que ultrapassa os limites geográficos, de tempo e de espaço consagrados na educação escolar presencial que se apóia na visão de um processo ensinoaprendizagem em sala de aula (conceito de borderless education). As universidades virtuais (UV) se enquadram nesse conceito.

As três universidades estaduais paulistas - USP, UNESP e UNICAMP - já têm massa crítica para iniciar um programa institucionalizado de educação baseada em novas tecnologias da informação e de comunicação (TICs). Desenvolvem, há alguns anos, pesquisas sobre o uso de tecnologias da informação e comunicação na educação, - tanto no que diz respeito à arquitetura de ambientes virtuais, como às metodologias de ensino/aprendizagem relacionadas - que já vem sendo utilizada por instituições públicas e privadas como plataformas para cursos de formação de pessoal ${ }^{1}$. A temática do ensino com base em novas TICs é abordada na seção a seguir.

\footnotetext{
${ }^{1}$ O Núcleo de Informática Aplicada à Educação (Nied), da Unicamp, por exemplo, investiga há 25 anos o uso da informática na Educação. No primeiro projeto, batizado de Educom e implantado em 1985, o Nied já concebia o computador como uma ferramenta de aprendizagem - e não como uma máquina de ensinar - por meio da qual o aluno poderia aprender por exploração e descoberta. A metodologia de ensino/aprendizagem foi aplicada em escolas públicas da região de Campinas - e até em fábricas -, numa iniciativa então inédita no país.
} 


\section{A EDUCAÇÃO COM BASE EM NOVAS TECNOLOGIAS}

A educação à distância é a modalidade educacional na qual a mediação didáticopedagógica nos processos de ensino e aprendizagem ocorre com a utilização de meios e tecnologias de informação e comunicação, envolvendo estudantes e professores no desenvolvimento de atividades educativas em lugares ou tempos diversos. Essa definição está presente no Decreto 5.622, de 19.12.2005 (que revoga o Decreto 2.494/98), que regulamenta o Art. 80 da Lei 9394/96 (LDB) ${ }^{2}$.

Trata-se de um processo de ensino-aprendizagem que não implica a presença física do professor ou no qual o professor está presente apenas em determinadas tarefas. Isso não significa reduzir a importância do professor na relação ensino-aprendizagem mas, ao contrário, exige a sua atenção multiplamente no preparo das aulas e do material didático, na pronta resposta e na aposta em um tipo de relação professor-aluno em que o diálogo entre os dois e entre o grupo envolvido deve ser uma constante (CASTRO, 2008).

As TICs têm sido utilizadas por diversos países para superar os limites de tempo e espaço e ampliar o acesso ao ensino superior, inclusive, tem sido intensamente utilizada hoje por diferentes empresas para capacitar funcionários que podem, assim, estudar sem se ausentarem do trabalho.

Esse modelo de ensino/aprendizagem foi implantado com sucesso na Universidade Aberta da Catalunha, na Espanha; na Open University, no Reino Unido; na Universidade Virtual de Monterrey, no México; na Télé-Université Québec, no Canadá; na Universidade Virtual de Pays de la Loire, na França; e na Universidade Nacional de Educação a Distância, na Espanha (Uned).

O Brasil também contabiliza experiências de ensino superior baseada em TICs como, por exemplo, o Consórcio Cederj/Cecierj, que reúne instituições de ensino superior do Rio de Janeiro; o Projeto Veredas, do governo do Estado de Minas Gerais; e, mais recentemente, a da Universidade Aberta do Brasil (UAB), criada pelo governo federal.

\footnotetext{
${ }^{2}$ No Brasil, as bases legais para a modalidade de educação a distância foram estabelecidas pela Lei de Diretrizes e Bases da Educação Nacional (Lei n. ${ }^{\circ}$ 9.394, de 20 de dezembro de 1996), que foi regulamentada pelo Decreto n. ${ }^{\circ}$ 5.622, publicado no D.O.U. de 20/12/05.
} 
No caso brasileiro, a educação baseada em TICs pode contribuir para a superação de um problema que adquiriu caráter emergencial: a carência de professores de Língua Portuguesa e de Ciências (Física, Química, Biologia e Matemática). O caso da Física, por exemplo, adquire contornos dramáticos. De acordo com o documento publicado pela Sociedade Brasileira de Física em 2006, todas as instituições de ensino superior do Brasil formaram, em 2002, apenas 305 licenciados em Física. O mesmo documento aponta para a necessidade de qualificar cerca de 55 mil professores de Física nos próximos dez anos ${ }^{3}$.

A educação com base em novas tecnologias de informação e de comunicação permite que o professor possa se capacitar sem se ausentar das aulas que ministra e possibilita que ele faça uma graduação de qualidade mesmo em regiões do Estado de São Paulo distantes dos campi das universidades públicas. É uma maneira eficaz de expandir as atividades das universidades públicas para além dos seus limites geográficos.

O Programa Univesp - Universidade Virtual do Estado de São Paulo tem como principal objetivo expandir o ensino superior no Estado de São Paulo por meio do aumento do número de vagas ofertadas pelas três universidades públicas (USP, UNESP e UNICAMP) e de sua melhor distribuição em todo o território paulista, como será tratado a seguir.

\section{O PROGRAMA UNIVESP}

O programa Univesp - Universidade Virtual do Estado de São Paulo, concebido pelo governo estadual, por meio da Secretaria de Ensino Superior (SES) ${ }^{4}$, foi criado pelo Decreto $\mathrm{n}^{\circ}$ 53.536, de 9 de outubro de 2008. Trata-se da resposta do governo paulista a um enorme desafio: o de expandir o ensino superior gratuito por meio da ampliação do número de vagas nas três universidades públicas paulistas - USP, UNICAMP E UNESP -, utilizando metodologia inovadora, que associa o uso intensivo das tecnologias de informação e comunicação às práticas tradicionais do ensino presencial que permitem uma grande qualidade na formação dos alunos.

\footnotetext{
${ }^{3}$ Esse quadro ajuda a explicar os maus resultados que os estudantes brasileiros têm obtido nas avaliações do Programa Internacional de Avaliação de Alunos (Pisa), da Organização para a Cooperação e o Desenvolvimento Econômico (OCDE) que mede o desempenho de alunos de 57 países.

${ }^{4}$ A Secretaria de Ensino Superior do Estado de São Paulo foi criada em $1^{\circ}$ de janeiro de 2007 pelo Governador José Serra, por meio do Decreto $\mathrm{n}^{\circ} 51.461$, e tem atribuição de propor políticas e diretrizes para o ensino superior, em todos os seus níveis.
} 
Como São Paulo e as universidades constituem um foco de convergência de estudantes vindos também de outras partes do país, o Univesp inscreve-se e, de certo modo, amplia e enfatiza o papel do estado no cenário das políticas públicas de educação superior com alcance nacional.

A estrutura consorciada do Univesp agrega ainda outras importantes instituições, entre elas a Fundação Padre Anchieta, a FAPESP, a Fundap, a Imprensa Oficial e o Centro Paula Souza.

Como se trata de um programa de ensino superior assentado sobre o uso intensivo das tecnologias de informação e de comunicação, além das práticas e das metodologias mais tradicionais de ensino, incluindo um componente significativo de atividades presenciais, o Univesp conta com um recurso que muito contribui para a sua singularidade no cenário do ensino superior público e gratuito no Brasil: a tecnologia televisiva.

A participação da Fundação Padre Anchieta no programa, com a implantação da tecnologia digital, permitiu que fosse criada a Univesp-TV, um canal aberto dedicado exclusivamente a programação da universidade virtual, com a transmissão de programas-aulas e programas complementares às atividades dos cursos, durante as 24 horas do dia. A digitalização da televisão representa um conjunto de transformações sócio-técnicas que pode potencializar a apropriação desta mídia como tecnologia educativa, pois integra recursos da mídia de massa com as tecnologias digitais de rede, torna-se potencialmente interativa e, assim, mais apropriada aos processos de aprendizagem (SCHAEFFER, 2008) ${ }^{5}$.

O Programa Univesp faz uso intensivo das tecnologias da informação e comunicação associadas a atividades presenciais em pólos de aprendizagem instalados em diversas regiões do Estado de São Paulo. Disponibiliza ambientes virtuais de aprendizagem na internet por meio do qual oferece conteúdos educacionais como material didático, artigos e vídeos; dispõe de ferramentas de acesso a atividades orientadas por tutores, organiza fóruns virtuais e chats que estreitam o relacionamento entre alunos do mesmo curso e permitem o compartilhamento de informações.

\footnotetext{
${ }^{5}$ Alguns autores já trabalham com a idéia de que a transição da TV analógica para a TV digital é um instrumento interativo de comunicação e de acesso às redes de informação para a inclusão social.
} 
O acompanhamento dos cursos e das atividades pedagógicas desenvolvidas em ambiente virtual também se realiza na forma presencial em pólos de apoio instalados nas universidades consorciadas, em instituições e órgãos públicos parceiros do programa, onde os alunos participam de atividades e assistem aos programas da Univesp TV, recebem apoio pedagógico e são avaliados.

\subsection{Características gerais do Programa Univesp}

\section{Público - alvo}

Pode-se identificar como alvo do programa todo o cidadão paulista com anseio de dedicar-se aos estudos de nível superior. Assim, o Programa Univesp tem como público-alvo os jovens com idade e qualificação para ingressar num curso superior; graduados interessados em ingressar em cursos de educação continuada; professores do Ensino Fundamental e Médio, Educação de Jovens Adultos e Educação Especial que não possuam diploma de curso superior, e os docentes graduados que desejem participar de programas de capacitação contínua ou que demandem curso de pós-graduação.

\section{Módulos Operacionais}

As atividades do Programa Univesp estão organizadas em três módulos voltados para os diversos públicos. O primeiro módulo tem como foco a formação de professores das redes pública e privada de Educação Básica do Estado de São Paulo.

O segundo módulo contempla, principalmente, a oferta de cursos de graduação em licenciatura nas áreas de Ciências, Matemática, Física, Química, Biologia, Língua Portuguesa, Filosofia e Sociologia que integram a grade curricular do ensino fundamental e médio.

O terceiro módulo oferece cursos de capacitação, extensão e pós-graduação para graduados em curso superior que desejam engajar-se em uma educação continuada com vista a seu aperfeiçoamento profissional. 


\section{Plataforma de Aprendizagem}

O Programa Univesp utiliza o ambiente virtual de aprendizagem conhecido como Tidia - Ae, desenvolvido no âmbito do programa Tecnologia da Informação para o Desenvolvimento da Internet Avançada (Tidia), financiado pela Fundação de Amparo à Pesquisa do Estado de São Paulo (FAPESP). O Tidia-Ae reúne mais de 150 pesquisadores de 23 laboratórios das principais universidades do Estado ancorados por quatro laboratórios centrais baseados na Escola Politécnica da USP, no Núcleo de Informática Aplicada à Educação da Unicamp, no Instituto Tecnológico da Aeronáutica (ITA) e no campus da USP em São Carlos. O objetivo do programa é formar recursos humanos e produzir pesquisas científicas e tecnológicas com aplicação na educação.

As pesquisas colaborativas, iniciadas em 2002, resultaram na criação de um ambiente de aprendizagem eletrônica (Ae) fundamentado numa arquitetura baseada em componentes que facilita a elaboração, manutenção e incorporação de novas funcionalidades ao longo do tempo.

O Tidia AE dá suporte a projetos de educação baseados em TICs que utilizam softwares livres, como é o caso do Programa Univesp. É formado por um conjunto de ferramentas computacionais integradas em ambiente de internet e que permite vários tipos de interação, bem como a agregação de diversas mídias, desde um programa de TV até a realização de fóruns de debates. Nesse ambiente, por exemplo, professores e tutores do curso podem propor, receber e corrigir exercícios, utilizando para tanto um espaço específico para essa finalidade.

Esse ambiente de aprendizagem permite ainda, a integração com sistemas administrativos das instituições parceiras do Programa Univesp, possibilitando sincronismo entre os sistemas de controle acadêmico e os de ensino e aprendizagem.

O Tidia - Ae baseia-se em padrões internacionais de concepção de ambientes de aprendizagem, como o consórcio internacional Projeto Sakai - comunidade que tem como objetivo analisar, desenvolver e distribuir um novo Collaboration and Learning Environment (CLC) - em iniciativas nacionais, como os projetos KyaTera, também patrocinado pela 
FAPESP. O próprio uso do Tidia-Ae deverá também motivar o desenvolvimento de novas pesquisas sobre o ensino mediado por tecnologia.

O Tidia - AE representa o Brasil na comunidade internacional de pesquisadores em aprendizagem eletrônica na condição de membro votante do IMS - Global Learning Consortium, uma iniciativa mundial de padronização em aprendizagem eletrônica e no Framework Sakai, um grupo de desenvolvimento para a expansão do núcleo básico do Sakai.

\section{Univesp TV}

A Fundação Padre Anchieta - que ao longo de 40 anos acumulou experiência na transformação de conteúdos pedagógicos em produtos audiovisuais - é parceira estratégica do Programa Univesp. No quadro da transição do sistema analógico de transmissão de TV para o sistema digital, a Fundação Padre Anchieta optou pela multiprogramação por meio de quatro canais abertos em São Paulo e disponibilizou um desses canais para a Univesp TV, exclusivamente dedicado ao Programa.

A Univesp TV tem sinal aberto, acessível por meio de aparelhos de TVs digital ou analógica equipada com conversor de sinal (set top box) e antenas parabólicas digitais, por meio do qual são transmitidos conteúdos dos cursos que integram o Programa Univesp. A matriz da programação da Univesp TV está disponível na área de informação da plataforma de cada um dos cursos.

A programação veicula material didático televisivo concebido especialmente para os cursos oferecidos pelo Univesp. Parte da programação - constituída por programas com 15 a 20 minutos de duração - tem caráter eminentemente pedagógico e está sincronizada com os horários de atividades presenciais realizadas nos vários pólos Univesp com o objetivo de complementar ou ilustrar as atividades propostas pelo tutor em sala de aula.

Outra parte da programação é constituída por programas complementares, de apoio ao processo de aprendizagem, e integra o portfólio de recursos multimídia dos vários cursos que podem ser acessados a distância. São programas curtos, semelhantes a verbetes eletrônicos. 
A grade de programação da Univesp TV inclui também a veiculação de documentários, entrevistas, filmes e debates, entre outros programas pautados pelas disciplinas dos vários cursos - como, por exemplo, conteúdos relacionados à História da Educação, à divulgação de atividades acadêmicas de pesquisa, entre outros.

Essa programação, que colabora para construção do conhecimento dos alunos do Univesp, também contribui para a difusão de informações de qualidade na audiência em geral.

\section{Apoio Telefônico - Help Desk}

O Programa dispõe, ainda, de um serviço de apoio telefônico acessível durante toda a semana, por meio do qual os alunos podem solucionar dúvidas sobre a utilização das ferramentas do ambiente virtual de aprendizagem. Essas orientações são fornecidas por técnicos que integram a equipe da plataforma Tidia-Ae.

\section{Pólos presenciais}

Além do ambiente virtual, o Programa Univesp opera no Estado de São Paulo também por meio de pólos presenciais para apoio pedagógico e acompanhamento de desempenho e avaliação dos alunos, instalados nos campi das instituições parceiras e em espaços físicos especificamente cedidos para esse fim por outras entidades públicas do Estado.

Os pólos atendem aos requisitos de infra-estrutura do Programa: contam com salas para as atividades pedagógicas equipadas com TV e/ou projetor multimídia, aparelhos para recepção do canal digital da Univesp TV e computadores com acesso à internet.

Nas salas instaladas nos pólos, os alunos se reúnem sob a orientação de um tutor para cada turma, sob a supervisão de um docente. Nos pólos eles esclarecem dúvidas, assistem aos programas transmitidos pela Univesp TV e realizam diversos tipos de atividades previstas no currículo dos cursos. Ali também são realizadas as avaliações presenciais, de acordo com cronograma e freqüência previstos em cada um dos cursos. 
Cada um dos pólos conta ainda com um monitor responsável pelas ações técnicoadministrativas necessárias à manutenção da infra-estrutura adequada para a realização dos cursos.

\section{Metodologias}

O Programa Univesp utiliza um modelo de ensino-aprendizagem baseado no uso de TICs para a realização de atividades pedagógicas associadas à presença de professores/tutores que, tanto em momentos presenciais como no ambiente virtual, assumem o papel de mediador, supervisor e até de animador do processo de formação dos alunos.

Com o apoio de ferramentas computacionais específicas do Tidia- Ae, os alunos matriculados têm acesso aos conteúdos especificamente preparados para cada curso, às ferramentas de interatividade e ao elenco de atividades que devem cumprir em cada uma das fases do curso, ao calendário de programas transmitidos pela Univesp TV, à lista de atividades individuais e em grupos, etc.

Cada atividade concluída é enviada para o conhecimento do tutor que avalia e orienta o aluno na evolução de suas atividades curriculares. Os trabalhos concluídos ficam armazenados em área de portfólio para consultas posteriores do próprio aluno, do tutor e orientadores, além dos colegas, quando autorizado pelo professor.

Na educação mediada por TICs, o cumprimento das tarefas, dentro do cronograma previsto, equivale à presença do aluno em sala de aula no modelo de educação presencial. Sua presença física, no entanto, será exigida sempre que a programação dos cursos incluírem atividades presenciais nos pólos como, por exemplo, em aulas de laboratório ou nas avaliações de cada unidade que compõe o curso.

\subsection{Programa Univesp: Estrutura e Funcionamento}

O Programa Univesp é gerido pela Secretaria de Ensino Superior do Estado de São Paulo por meio de um Comitê Diretivo com competências consultivas, normativas e deliberativas. Este Comitê é presidido pelo Secretário de Ensino Superior e formado por representantes das instituições parceiras. 


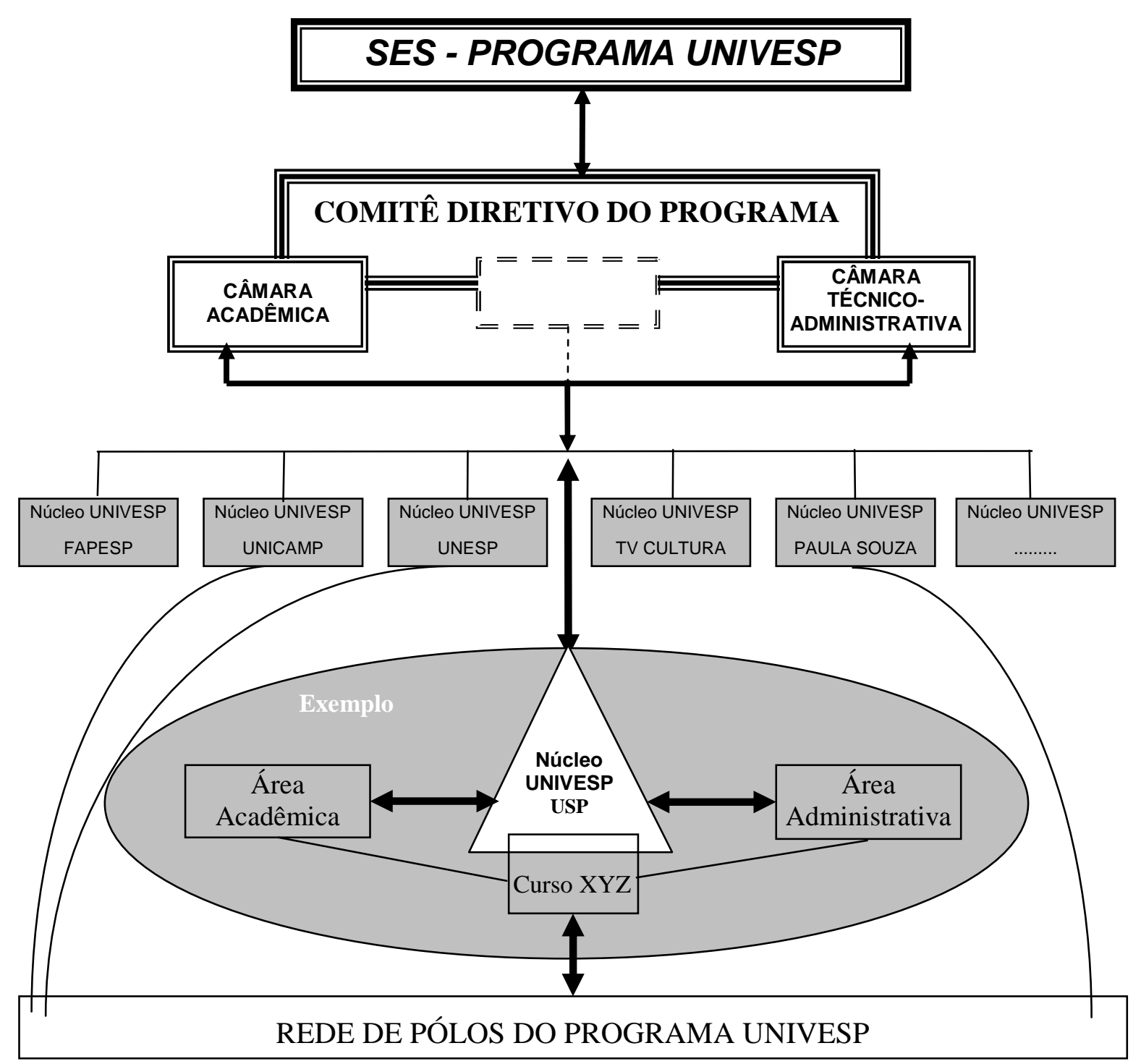

FIGURA 1 - Estrutura organizativa do Programa Univesp

A parceria entre a Secretaria de Ensino Superior e as instituições parceiras é formalizado por meio de um Termo de Cooperação mútua com o propósito de estabelecer cooperação técnica para a implementação do Programa Univesp.

Cabe à Secretaria de Ensino Superior (SES) propor ao Comitê Diretivo do Programa, diretrizes e padrões acadêmicos, técnicos, administrativos e financeiros a serem seguidos para o desenvolvimento e operação de cursos a serem vinculados ao Programa. 
A SES também oferecerá condições para que as Câmaras do Comitê Diretivo possam acompanhar, analisar, avaliar e submeter ao Comitê relatórios circunstanciados sobre o andamento dos cursos bem como do cumprimento dos requisitos e diretrizes por ele estabelecidos.

\section{CONSIDERAÇÕES FINAIS}

O Estado de São Paulo abriga a maior rede de instituições de pesquisa do país, consolidada por meio de uma política pautada pela autonomia das instituições de ensino superior, de investimentos na qualidade dos sistemas de graduação, pós-graduação e extensão e de fomento à pesquisa. A necessidade, agora, é a expansão do ensino superior com o objetivo de ampliar o número de vagas oferecidas pelas três universidades públicas paulistas e contribuir para a ampliação de sua distribuição geográfica.

Um dos pilares desse processo de expansão do ensino superior público paulista é o Programa Univesp - Universidade Virtual do Estado de São Paulo, coordenado pela Secretaria do Ensino Superior do Estado de São Paulo.

O programa tem forte utilização das TICs, que promoveram profundas mudanças nos padrões de comunicação entre as pessoas e globalizaram o mundo dos negócios, patrocinam agora uma verdadeira revolução no modelo de educação tradicional. Desconhecem limites de tempo e espaço e, por isso, permitem ampliar a abrangência da escola para além da sala de aula, reproduzindo a relação ensino/aprendizagem em ambiente virtual dotado de ferramentas específicas e orientado por metodologias desenvolvidas para esse fim.

Associadas a atividades presenciais, as TICs conferem nova dinâmica à relação professor-aluno, ampliam as redes de relacionamento e de colaboração entre alunos do mesmo curso, facilitam o acesso aos conteúdos e permitem a incorporação de novas mídias.

O desafio do Programa UNIVESP é buscar novos modelos de ensino/aprendizagem que democratizem o acesso ao conhecimento a partir do uso das novas tecnologias da informação e comunicação, além de oferecer múltiplos recursos de acesso à informação e de interatividade que permitem uma grande qualidade na formação dos alunos. 


\section{REFERÊNCIAS}

BARBOSA FILHO, A.; CASTRO, C. A convergência digital analisada sob o prisma da nova ordem tecnológica. In: CONGRESSO DA COMPÔS. 2006, Bauru. Anais eletrônicos... Bauru: UNESP, 2006. Disponível em: <http://www.faac.unesp.br/>. Acesso em: fev.2009. .; ___ _ TOME, T. Mídias digitais, convergência tecnológica e inclusão social. São Paulo, SP: Paulinas, 2005.

CASTRO, C. EAD e TV Digital - a co-autoria na aprendizagem. In: XXXI CONGRESSO BRASILEIRO DE CIÊNCIAS DA COMUNICAÇÃO - INTERCOM - SOCIEDADE BRASILEIRA DE ESTUDOS INTERDISCIPLINARES DA COMUNICAÇÃO. Natal, 2008. Anais eletrônicos... Natal: Intercom: 2008.

Disponível em: 〈http://www.intercom.org.br/papers/nacionais/2008/resumos/R3-0507-1.pdf > Acesso em: fev.2009.

DIAZ BORDENAVE, J. Televisão Digital e Inclusão Social - uma proposta de democratização para as novas tecnologias de comunicação. In: SEMINÁRIO INTERNACIONAL SOBRE POLÍTICAS PÚBLICAS DA ASSOCIACIÓN LATINOAMERICANA DE COMUNICACIÓN (ALAIC). Anais... São Paulo, SP: USP, 2005.

ORGANIZAÇÃO DAS NAÇÕES UNIDAS - UNESCO. Las Tecnologías de la Información y la Comunicación en la Formación Docente- guía de planificación. Paris: Francia, 2004.

SCHAEFFER, Olmiro Cristiano Lara. Premissas para apropriação da TV digital interativa em processos educativos. In: XXXI CONGRESSO BRASILEIRO DE CIÊNCIAS DA COMUNICAÇÃO - INTERCOM - SOCIEDADE BRASILEIRA DE ESTUDOS INTERDISCIPLINARES DA COMUNICAÇÃO. Natal, 2008. Anais eletrônicos... Natal: Intercom, 2008. Disponível em: http://www.intercom.org.br/papers/nacionais/2008/resumos/R3-2191-1.pdf Acesso em: fev.2009.

VOGT, C. O conhecimento, as universidades e seus desafios. In: MORHY, L. (Org.). Universidade em questão. Brasília: UnB, 2004. p. 83-97.

WOLF, A. Does Education Matter? Myths About Education and Economic. Growth: Penguin business, 2002. 
CARLOS VOGT

Poeta e lingüista, foi reitor da Universidade Estadual de Campinas Unicamp (1990-1994) e presidente da Fundação de Amparo à Pesquisa no Estado de São Paulo - FAPESP (2002-2007).

Coordenador do Laboratório de Estudos Avançados em Jornalismo (Labjor/Unicamp) e Secretário de Ensino Superior do Estado de São Paulo.

E-mail: cvogt@uol.com.br

Recebido em: 01/03/2009

Publicado em: 30/06/2009 